\title{
Epidemiological Characteristics and Outcome of Open Globe Injuries in Tabuk City, Kingdom of Saudi Arabia: Retrospective Cohort Study
}

\author{
Naif Alali · Hani B. ALBalawi · Alanuad Albazei · Moustafa Magliyah • \\ Muhammad Usman · Fatehulalim Alamin • Omar Ahmed • \\ Mohammed A. Hazzazi · Raghad Albalawi · Rawan Alzahrani • \\ Taiba Khokhar · Alhanouf Alatawi · Abdulrahman ALDarrab
}

Received: December 3, 2021 / Accepted: January 26, 2022 / Published online: February 12, 2022

(C) The Author(s) 2022

\section{ABSTRACT}

Introduction: The objective of this study was to assess the epidemiological characteristics, clinical features and visual outcomes of open globe eye injury (OGI) in Tabuk, Saudi Arabia.

Methods: A retrospective chart review of OGI patients who had undergone operative repair of their injuries in Tabuk, Saudi Arabia. The collected data included patients' demographics, duration between trauma and presentation and the mechanism of trauma, wound location,

N. Alali · H. B. ALBalawi

Division of Ophthalmology, Department of Surgery, Faculty of Medicine, University of Tabuk, Tabuk,

Saudi Arabia

A. Albazei

Department of Medical Education, King Khaled Eye Specialist Hospital, Riyadh, Saudi Arabia

\section{Magliyah}

Department of Ophthalmology, Prince Mohammed Medical City, Aljouf, Saudi Arabia

\section{Usman}

Department of Ophthalmology, King Fahd

Specialist Hospital, Tabuk, Saudi Arabia

F. Alamin · O. Ahmed · T. Khokhar

Department of Ophthalmology, King Khalid

Hospital, Tabuk, Saudi Arabia

M. A. Hazzazi

Division of Ophthalmology, Department of Surgery,

National Guard Hospital, Riyadh, Saudi Arabia extent of injury, presence of intraocular foreign body, and initial and final visual acuity data.

Results: Sixty-three eyes of 63 patients who were admitted for traumatic globe rupture were included; $84.1 \%$ were males and $39.7 \%$ were of pediatric age. Delay in seeking medical care for $>24 \mathrm{~h}$ was recorded in $4.8 \%$ of patients. The most common (42.9\%) mechanism was blunt trauma followed by sharp trauma $(38.1 \%)$ and projectile trauma $(9.5 \%) ; 55.6 \%$ had the injury in zone 1 . Intraocular foreign body was reported in $9.5 \%$ of patients. Intraocular foreign bodies

\section{A. Hazzazi}

King Saud Bin Abdulaziz University for Health Sciences, Riyadh, Saudi Arabia

\section{R. Albalawi · R. Alzahrani · A. Alatawi}

Department of Ophthalmology, Ministry of Health, Riyadh, Saudi Arabia

\section{A. ALDarrab \\ Department of Surgery, College of Medicine, Prince Sattam Bin Abdulaziz University, Al-Kharj, Saudi} Arabia

\section{H. B. ALBalawi ( $\square)$}

Department of Ophthalmology, University of Tabuk, Al- Douba Street, PO Box 7191, Tabuk 11462, Kingdom of Saudi Arabia e-mail: hb.albalawi@ut.edu.sa 
were significantly more common in adults $(p=0.018)$ compared to children. Poor visual acuity was noted in $77.8 \%$ of patients upon presentation and $60.3 \%$ on last visit.

Conclusion: The incidence of OGI was more common in males. The most common cause of OGI was blunt injury, and half of the injuries were in zone 1 . Visual outcomes are guarded for most patients with OGIs.

Keywords: Corneal laceration; Eye trauma; Intraocular foreign body; Open globe; Injury; Visual impairment

\section{Key Summary Points}

Why carry out this study?

Ocular trauma has been reported to be one of the main contributors to unilateral partial or total loss of sight. Although open globe injuries (OGIs) comprised only $2 \%$ of all ocular injuries, they were responsible for $44 \%$ of expenditure on ocular injuries in addition to impact on the individual and their family, the health system and society

What did the study ask and what was its hypothesis?

To assess the epidemiological characteristics, clinical features and visual outcomes of open globe eye injury (OGI) in Tabuk, Saudi Arabia

\section{What was learned from the study?}

Open globe injuries were dominant in males, the most common cause of OGI was the blunt injury, and half of the injuries were in zone 1 . Visual outcomes are guarded for most patients with OGIs

The result of this study should encourage us to increase the awareness to minimize the incidence and complications of OGIs

\section{INTRODUCTION}

Ocular trauma has variable clinical outcomes, ranging from favorable outcomes to total blindness. Globally, ocular trauma is one of the major causes of visual impairment, especially in the working age group [1, 2]. Furthermore, ocular trauma is one of the main contributors to unilateral partial or total loss of sight [3]. Although both eyes constitute only $0.2 \%$ of the total and $0.52 \%$ of the anterior surface area of the human body, they are the third most common organ affected by traumatic injuries after the hands and feet [4]. According to the Birmingham Eye Trauma Terminology System (BETT), eye injury is divided into either closed or open globe injury (OGIs) depending on the presence or absence of a full-thickness wound of the eye wall. Closed eye injury is further subdivided into either lamellar laceration (partial thickness wound of the eye wall) or contusion. OGI is subdivided into eye wall laceration (fullthickness wound of the eye wall caused by a sharp object) or ruptured globe (full thickness wound of the eye wall caused by a blunt object). Laceration is divided into penetration (with only an entry wound) and perforation (with entry and exit wounds) [5]. Figure 1 summarizes the different types of eye injuries according to the BETT system. Although OGIs comprised only $2 \%$ of all ocular injuries in Australia, for example, they were responsible for $44 \%$ of expenditure on ocular injuries in addition to having an impact on the individual and their family, the health system and society [6, 7]. OGIs have been classified according to site of injury into three zones; the zone of injury is defined according to the Ocular Trauma Classification Group: zone 1 (the whole cornea, including the corneoscleral limbus), zone 2 (corneoscleral limbus to a point $5 \mathrm{~mm}$ posterior to the sclera) and zone 3 (posterior to anterior $5 \mathrm{~mm}$ of the sclera) [8].

Despite the consequences of eye trauma at the individual and community levels, data on the prevalence of this condition and its epidemiological characteristics are limited globally. However, in a review study conducted in 1998 Négrel et al. reported that ocular injuries 
were responsible for 19 million cases of blindness worldwide; additionally, 55 million individuals suffered a restriction in their daily activity because of ocular injuries. The estimated incidence of OGIs is around 3.5 cases in 100,000 annually, leading to around 200,000 OGIs every year worldwide [1]. Similar numbers were also reported in the USA as estimated cases of globe rupture are approximately 3 per 100,000 annually [9].

More specifically, many studies found that OGI is a leading cause of hospitalizations and poor visual outcomes compared to closed globe injuries $[10,11]$.

The main objectives of surgical OGI operations are preserving vision by closing the primary wound, repositioning prolapsed ocular contents or debridement of extruded tissues for $>24 \mathrm{~h}$, removing intraocular foreign bodies and avoiding further complications [9].

Improvements in the general population's knowledge about the pathophysiology, availability of treatment as well as advances in the instruments and OGI surgery techniques have enhanced the efficacy and safety of OGI management [12].

Successful OGIs are dependent upon several associated factors, such as the severity of the initial injury, preoperative visual acuity, presence of intraocular foreign bodies, time between trauma incidence and hospital admitting [13].

The aim of this study was to assess the clinical characteristics of OGI patients admitted to King Khalid Hospital (KKH) and King Fahd Specialist Hospital (KFSH), Saudi Arabia, and to investigate the final visual outcomes of treated patients. This might represent the first step in any interventional programs aiming to prevent and improve outcomes of OGIs.

\section{METHODS}

\section{Ethical Statement}

This study followed the tenets of the Declaration of Helsinki. It was approved by the Research Ethics Committee of University of Tabuk approval number READ 0051.

\section{Study Design and Setting}

This is a retrospective cohort study of OGI patients who underwent operative repair of their eye injuries in $\mathrm{KKH}$ and $\mathrm{KFSH}$, Tabuk, Saudi Arabia. Both hospitals are governmentowned hospitals which provide secondary eye care and were established in 1983 and 2013, respectively. They provide mostly free services and receive about 30,000 patients per year. Both hospitals are in Tabuk, North-Western Region, Saudi Arabia, an approximately $4 \mathrm{~h}$ drive from the Holy City of Madinah. The two units are about $5 \mathrm{~km}$ apart and work separately.

\section{Data Collection}

The collected data include demographic data, interval between trauma incidence and presentation and mechanism of trauma, wound location, extent of the eye injury, zone of injury, presence of intraocular foreign body, and initial and final visual acuity data. The zone of injury was classified according to the Ocular Trauma Classification Group.

\section{Statistical Analysis}

Statistical analysis was carried out using a Student's two-tailed $t$-test and chi-square using Statistical Package for Social Sciences (SPSS) for Windows, version 26 (IBM Corp., Armonk, NY, USA). Correlation was considered significant if values were $<0.05$.

\section{RESULTS}

The present study included 63 patients who were admitted to $\mathrm{KKH}$ and KFSH during 2014-2019. Most (61.7\%) patients were Saudis, while non-Saudi patients represented $38.4 \%$. More than one-third (39.7\%) of the patients were $<10$ years old; the second most frequent age group was 30 to $<40$ years old $(17.5 \%)$, while injuries were the least in those aged $>$ 40 years $(12.7 \%)$. Children ( $<18$ years old) accounted for $52.4 \%$ of the studied patients, whereas adults accounted for $47.6 \%$. Male 


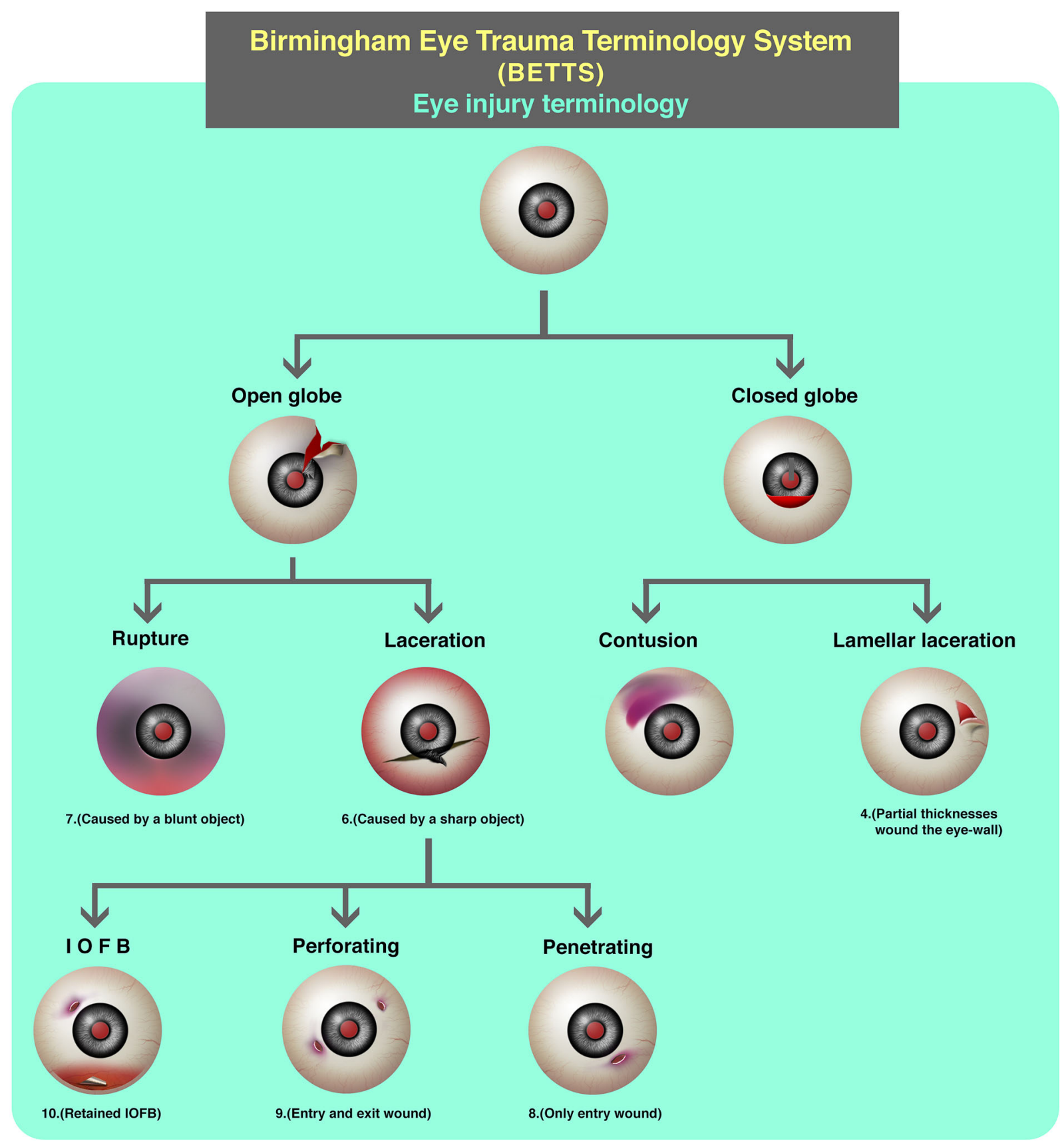

Fig. 1 Different types of eye injuries according to the BETT system

patients outnumbered the females $(84.1 \%$ vs. $15.9 \%)$. Most $(90.5 \%)$ patients did not suffer from chronic medical conditions. Table 1 summarizes the studied patients' characteristics.

Table 2 demonstrates the circumstances of trauma in the patients in our series. The time interval between trauma infliction and presentation to medical care was not recorded in $49.2 \%$ of cases, but this interval was $\leq 24 \mathrm{~h}$ in $41.3 \%$ of patients. Delay in seeking medical care till the next $24 \mathrm{~h}$ or even after $48 \mathrm{~h}$ was recorded in $4.8 \%$ of patients each. The side of affected eye was not recorded in $7.9 \%$ of cases, and the rates of affection of right and left eyes were $50.8 \%$ 
Table 1 Patient characteristics (total $n=63$ )

\begin{tabular}{lrr}
\hline & $n$ & $\%$ \\
\hline Nationality & & \\
Saudi & 40 & 63.5 \\
Non-Saudi & 23 & 36.5 \\
Age groups & & \\
$<1$ to $<10$ years & 25 & 39.7 \\
10 to $<20$ years & 9 & 14.3 \\
20 to $<30$ years & 10 & 15.9 \\
30 to $<40$ years & 11 & 17.5 \\
40 years or above & 8 & 12.7 \\
Age categories & & \\
Children & 33 & 52.4 \\
Adults & 30 & 47.6 \\
Gender & & \\
Female & 10 & 15.9 \\
Male & 53 & 84.1 \\
Comorbidities & & \\
No & 57 & 90.5 \\
Yes & 6 & 9.5 \\
Bronchial asthma & 2 & 3.2 \\
Diabetes mellitus, hypertension, bronchial \\
asthma & 1 & 1.6 \\
Allergic rhinitis & & \\
Congenital heart disease, pulmonary & 1 & 1.6 \\
hypertension & & 1.6 \\
Smoking & & \\
\hline & & \\
\hline
\end{tabular}

and $41.3 \%$, respectively. The mechanism of inflicted trauma widely varied among the patients, but we endeavored to categorize the different mechanisms under the broad terms of blunt, sharp and projectile trauma. The mechanism was not documented in the patients' files in $9.5 \%$ of cases. The most common $(42.9 \%)$ mechanism was blunt trauma, which was inflicted mostly by falls and collision of a blunt object with the eye, e.g., a thrown stone or penetration by tree branches or pens. Sharp trauma was reported in $38.1 \%$ of cases and projectile trauma by metals or glass shards in $38.1 \%$ and $9.5 \%$ of cases, respectively. Approximately half the patients had injury in zone 1 , $30.2 \%$ in zone 2 and $7.9 \%$ in zone 3 . The remaining cases had injuries extending to more than one zone. The presence of an intraocular foreign body was reported in $9.5 \%$ of cases. Comparison of proportions between the studied children and adults did not reveal significant difference regarding the interval between trauma and presentation to medical care $(p=0.765)$, though higher percentages of delay were observed in adults, laterality $(p=0.801)$, mechanism of trauma $(p=0.345)$ and extent of injury ( $p=0.568)$. However, intraocular foreign bodies were found only in adults $(p=0.018)$ compared to children.

Various types of eye injuries documented in the studied patients are outlined in Table 3. Most injuries were reported in a small number of patients; hence, comparison of proportions between children and adults was not performed. However, there seemed to be a higher percentage of injuries to the posterior eye segment in adults compared to children as inferred from the rates of vitreous humor and retinal injuries.

Table 4 compares the initial visual acuity status on admission and the final visual acuity in the studied patients. Average duration of follow-up was $13.1 \pm 5.6$ months. While most patients had poor vision on presentation (77.8\%) and on last visit (60.3\%), improvement in visual acuity was observed in some patients, but this improvement was not statistically significant $(p=0.250)$. However, the visual acuity on admission (15.9\%) or discharge $(27 \%)$ was not documented in the file in a considerable proportion of patients. There was a significant relationship between final visual acuity and patients' age $(p=0.049)$, while relationships with initial visual acuity $(p=0.131)$, gender $(p=0.319)$, extent of injury $(p=0.169)$, $(p=0.201)$, presence of foreign body $(p=0.511)$, lens status $(p=0.684)$ and ocular complications $(p=0.166)$ were not significant. 
Table 2 Circumstances of trauma, laterality and presenting visual acuity (total $n=63$ )

\begin{tabular}{|c|c|c|c|c|c|c|c|}
\hline & \multicolumn{2}{|c|}{ Children $(n=33)$} & \multicolumn{2}{|c|}{ Adults $(n=30)$} & \multicolumn{2}{|c|}{ Total $(n=63)$} & \multirow[t]{2}{*}{$p$} \\
\hline & $N$ & $\%$ & $n$ & $\%$ & $n$ & $\%$ & \\
\hline \multicolumn{8}{|c|}{ Interval between trauma and presentation } \\
\hline$\leq 24 \mathrm{~h}$ & 15 & 45.5 & 11 & 36.7 & 26 & 41.3 & $0.765^{\mathrm{a}}$ \\
\hline$>24-48 \mathrm{~h}$ & 2 & 6.1 & 1 & 3.3 & 3 & 4.8 & \\
\hline$>48 \mathrm{~h}$ & 1 & 3.0 & 2 & 6.7 & 3 & 4.8 & \\
\hline Not recorded & 15 & 45.5 & 16 & 53.3 & 31 & 49.2 & \\
\hline \multicolumn{8}{|l|}{ Laterality } \\
\hline Left & 13 & 39.4 & 13 & 43.3 & 26 & 41.3 & $0.801^{\mathrm{a}}$ \\
\hline Right & 18 & 54.5 & 14 & 46.7 & 32 & 50.8 & \\
\hline Not recorded & 2 & 6.1 & 3 & 10.0 & 5 & 7.9 & \\
\hline \multicolumn{8}{|l|}{ Mechanism of trauma } \\
\hline Blunt & 16 & 48.5 & 11 & 36.7 & 27 & 42.9 & $0.345^{\mathrm{a}}$ \\
\hline Sharp & 13 & 39.4 & 11 & 36.7 & 24 & 38.1 & \\
\hline Projectile & 1 & 3.0 & 5 & 16.7 & 6 & 9.5 & \\
\hline Not recorded & 3 & 9.1 & 3 & 10.0 & 6 & 9.5 & \\
\hline \multicolumn{8}{|l|}{ Extent of injury } \\
\hline Zone 1 & 21 & 63.6 & 14 & 46.7 & 35 & 55.6 & $0.568^{\mathrm{a}}$ \\
\hline Zone 2 & 9 & 27.3 & 10 & 33.3 & 19 & 30.2 & \\
\hline Zone 3 & 2 & 6.1 & 3 & 10.0 & 5 & 7.9 & \\
\hline Zone 1 and zone 2 & 0 & 0.0 & 2 & 6.7 & 2 & 3.2 & \\
\hline Zone 2 and zone 3 & 1 & 3.0 & 1 & 3.3 & 2 & 3.2 & \\
\hline \multicolumn{8}{|c|}{ Presence of intraocular foreign body } \\
\hline No & 30 & 90.9 & 21 & 70.0 & 51 & 81.0 & $0.018^{* a}$ \\
\hline Yes & 0 & 0.0 & 6 & 20.0 & 6 & 9.5 & \\
\hline Not recorded & 3 & 9.1 & 3 & 10.0 & 6 & 9.5 & \\
\hline
\end{tabular}

*Significant at $p \leq 0.05$

${ }^{\mathrm{a}}$ Fisher-Freeman-Halton exact test

\section{DISCUSSION}

The present study included 63 patients who were admitted to $\mathrm{KKH}$ and $\mathrm{KFSH}$ to undergo OGIs. Most (61.7\%) patients were Saudi and males $(84.1 \%)$. More than one-third (39.7\%) of the patients were children. Tabuk is the biggest urban area in the north of Saudi Arabia. It is served by three hospitals, KKH, KFSH and the maternity and children's hospital. All are government-owned hospitals, which provide secondary health care and were established in 1983, 2013 and 2019, respectively. They provide mostly free services and receive about 30,000 
Table 3 Pattern of injuries in the studied patients (total $n=63$ )

\begin{tabular}{|c|c|c|c|c|c|c|}
\hline & \multicolumn{2}{|c|}{ Children $(n=33)$} & \multicolumn{2}{|c|}{ Adults $(n=30)$} & \multicolumn{2}{|c|}{ Total $(n=63)$} \\
\hline & $N$ & $\%$ & $n$ & $\%$ & $n$ & $\%$ \\
\hline \multicolumn{7}{|l|}{ Lids } \\
\hline Laceration & 1 & $3.0 \%$ & 0 & $0.0 \%$ & 1 & $1.6 \%$ \\
\hline \multicolumn{7}{|l|}{ Sclera } \\
\hline Laceration & 0 & 0.0 & 4 & 13.3 & 4 & 6.3 \\
\hline \multicolumn{7}{|l|}{ Cornea } \\
\hline Keratitis & 1 & 3.0 & 0 & 0.0 & 1 & 1.6 \\
\hline Tear & 4 & 12.1 & 5 & 16.7 & 9 & 14.3 \\
\hline Abrasion/ulcer & 2 & 6.1 & 1 & 3.3 & 3 & 4.8 \\
\hline \multicolumn{7}{|l|}{ Anterior chamber } \\
\hline Hyphema & 9 & 27.3 & 14 & 46.7 & 23 & 36.5 \\
\hline Hypopyon (endophthalmitis) & 1 & 3.0 & 0 & 0.0 & 1 & 1.6 \\
\hline \multicolumn{7}{|l|}{ Iris } \\
\hline Iris prolapse & 11 & 33.3 & 11 & 36.7 & 22 & 34.9 \\
\hline \multicolumn{7}{|l|}{ Lens } \\
\hline Cataract & 8 & 24.2 & 9 & 30.0 & 17 & 27.0 \\
\hline Dislocated intraocular lens & 0 & 0.0 & 1 & 3.3 & 1 & 1.6 \\
\hline \multicolumn{7}{|l|}{ Vitreous humor } \\
\hline Uveal and vitreous prolapse & 2 & 6.1 & 6 & 20.0 & 8 & 12.7 \\
\hline Vitreous hemorrhage & 0 & 0.0 & 4 & 13.3 & 4 & 6.3 \\
\hline Vitreous loss & 1 & 3.0 & 4 & 13.3 & 5 & 7.9 \\
\hline \multicolumn{7}{|l|}{ Retina } \\
\hline Hemorrhage & 1 & 3.0 & 0 & 0.0 & 1 & 1.6 \\
\hline Maculopathy & 0 & 0.0 & 1 & 3.3 & 1 & 1.6 \\
\hline Optic nerve avulsion & 1 & 3.0 & 0 & 0.0 & 1 & 1.6 \\
\hline Retinal detachment & 0 & 0.0 & 4 & 13.3 & 4 & 6.3 \\
\hline
\end{tabular}

patients/year. Tabuk city, located in the northwestern region of Saudi Arabia, is an approximately $4 \mathrm{~h}$ drive from the Holy City of Madinah Almonawwarah.

Several studies had reported a higher risk of OGI among males and children [3, 14-16]. This is in agreement with our results, as most patients were males (84.1\%) and more than half of them were $<18$ old (52.4\%). This indicates the preponderance of these populations due to work, sporting activities or school-associated activities. Eye injuries were dominant in males because of work-related injuries. This could be 
Table 4 Comparison of initial and final visual acuity

\begin{tabular}{|c|c|c|c|c|c|}
\hline & \multicolumn{2}{|c|}{$\begin{array}{l}\text { Initial VA } \\
\text { grade }\end{array}$} & \multicolumn{2}{|c|}{$\begin{array}{l}\text { Final VA } \\
\text { grade }\end{array}$} & \multirow[t]{2}{*}{$p$} \\
\hline & $\bar{N}$ & $\%$ & $\bar{N}$ & $\%$ & \\
\hline Good (6/36 or better) & 4 & 6.3 & 6 & 9.5 & $0.250^{\mathrm{a}}$ \\
\hline Moderate $(6 / 60-1 / 60)$ & 0 & 0.0 & 2 & 3.2 & \\
\hline Poor $(<1 / 60)$ & 49 & 77.8 & 38 & 60.3 & \\
\hline Not recorded & 10 & 15.9 & 17 & 27.0 & \\
\hline
\end{tabular}

${ }^{a}$ Marginal homogeneity test

Table 5 Suggestions for the prevention of eye injuries

\begin{tabular}{|c|c|}
\hline Place & Advice to consider \\
\hline Home & $\begin{array}{l}\text { Keep sharp objects away from children } \\
\text { and look for safety standards in } \\
\text { household products, supervise your } \\
\text { child's use of tools such as pencils, } \\
\text { scissors and forks }\end{array}$ \\
\hline $\begin{array}{l}\text { Industry and } \\
\text { agriculture }\end{array}$ & $\begin{array}{l}\text { Emphasize the use of helmets and eye } \\
\text { protection, keep children away from } \\
\text { flying debris }\end{array}$ \\
\hline Sports & $\begin{array}{l}\text { Encourage the use of eye protection } \\
\text { and/or helmets, e.g., for contact } \\
\text { sports }\end{array}$ \\
\hline Transport & $\begin{array}{l}\text { Encourage motorists to wear seatbelts } \\
\text { and cyclists and motorcycle users to } \\
\text { wear eye protection }\end{array}$ \\
\hline
\end{tabular}

decreased by proper education and use of safety equipment [6,17-21].

In our study, more than half of the patients $(52.4 \%)$ were $<18$ years old and $39.7 \%<10$ years.

In the US, about 2.4 million OGIs occur annually, 35\% of them in children [8]. OGIs in children are more severe and lead to higher risk of complications, longer hospitalization stay and poorer visual outcomes [22-27].
The current results show that approximately half the cases had injuries in zone $1,30.2 \%$ in zone 2 and $7.9 \%$ in zone 3 . In agreement with these results, several studies have reported that Zone 1 injuries are also the most common form of OGI among pediatric patients (44-79\%) [28-33].

In the current study, intraocular foreign bodies were reported in $9.5 \%$ of cases, all of which were adults, which showed statistical significance $(p=0.018)$.

Patel et al. carried out a study on 527 patients with traumatic OGI in the USA; $14 \%$ of patients had surgically confirmed intraocular foreign bodies, which is more than found in our result. They found that metal and glass were the most frequent foreign bodies. Most the injuries were in the posterior segments [34].

Blunt trauma was found to be the most common cause of OGI in our study (42.9\%). Similar findings were reported by Nirmalan et al. who found that blunt injuries (54.9\%) were the major cause of OGIs [35].

Injuries due to sharp objects represented half of the causes of the eye injuries in the Makhrash and Gosadi study [14]. However, another study reported that most OGI patients were injured by wire used in greenhouses [16].

Additionally, Rahman et al. found that injury by sharp objects $(66 \%)$ is the most common mechanism of eye injury [21].

In the current study, improvement in visual acuity was observed in some patients as evidenced by the increase in the percentage of good and moderate visual acuity grades while the rate of poor vision decreased, but this difference did not reach statistical significance $(p=0.250)$.

The rate of successful treatment (final VA of $20 / 40$ or better) after OGIs is between 54 and $56.5 \%$ in industrialized countries $[11,25,36]$ with a less favorable prognosis in non-industrialized countries (15.5-25.7\%) [29, 31, 37, 38]. The most common causes of poor final visual acuity in children who have undergone OGIs are residual corneal opacity and amblyopia [39].

The results of this study encourage raising the level of awareness regarding this preventable cause of visual impairment at both local and worldwide levels by educating 
individuals at risk such as building workers and encouraging them to use protective eyewear during high-risk work. Table 5 summarizes some advice to reduce the risk of eye injuries in different areas.

Limitations of this study include the small sample size, short duration and unavailability of data regarding socioeconomic status of patients and its effect on type and pattern of injury.

\section{CONCLUSION}

It was concluded that OGIs were dominant in males and children. The most common cause of OGI was blunt injury, and half of the injuries were in zone 1 . There is no significant difference between OGIs in children and adults, except that intraocular foreign bodies were only reported in adults.

\section{ACKNOWLEDGEMENTS}

Funding. No funding or sponsorship was received for this study or publication of this article. The journal's Rapid Service Fee was funded by the authors.

Authorship. All named authors meet the International Committee of Medical Journal Editors (ICMJE) criteria for authorship for this article, take responsibility for the integrity of the work as a whole, and have given their approval for this version to be published.

Author Contributions. Alanuad Albazei, Rawan Alzahrani, Muhammad Usman, Fatehulalim Alamin, Omar Ahmed and Raghad Albalawi collected and analyzed the data. Alali wrote the introduction. Hani Albalawi and Alhanouf Alatawi wrote the results. Mohammed A. Hazzazi, Abdulrahman AlDarrab, Moustafa Magliyah and Taiba Khokhar wrote the discussion. The manuscript was revised by Hani Albalawi and Moustafa Magliyah. All authors have read and agreed to the published this version of the manuscript.
Compliance with Ethics Guidelines. This study followed the tenets of the Declaration of Helsinki. It was approved by the Re-search Ethics Committee of University of Tabuk approval number READ 0051.

Disclosures. Naif Alali, Hani B ALBalawi, Alanuad Albazei, Moustafa Magliyah, Muhammad Usman, Fatehulalim Alamin, Omar Ahmed, Mohammed A. Hazzazi, Raghad Albalawi, Rawan Alzahrani, Taiba Khokhar, Alhanouf Alatawi and Abdulrahman AlDarrab have nothing to disclose.

Data Availability. All data generated or analyzed during this study are included in the results section of this published article.

Open Access. This article is licensed under a Creative Commons Attribution-NonCommercial 4.0 International License, which permits any non-commercial use, sharing, adaptation, distribution and reproduction in any medium or format, as long as you give appropriate credit to the original author(s) and the source, provide a link to the Creative Commons licence, and indicate if changes were made. The images or other third party material in this article are included in the article's Creative Commons licence, unless indicated otherwise in a credit line to the material. If material is not included in the article's Creative Commons licence and your intended use is not permitted by statutory regulation or exceeds the permitted use, you will need to obtain permission directly from the copyright holder. To view a copy of this licence, visit http:// creativecommons.org/licenses/by-nc/4.0/.

\section{REFERENCES}

1. Négrel AD, Thylefors B. The global impact of eye injuries. Ophthalmic Epidemiol. 1998;5:143-69.

2. Albazei AI, Ahmed $\mathrm{OH}$, AlAli NM, Alselaimy RM, Alreshidi SO, Magliyah MS, Albalawi HB. Poor outcome in camel-related eye trauma with ruptured globe. Int Med Case Rep J. 2021;7(14):219-22. https://doi.org/10.2147/IMCRJ.S305158.PMID: 33854383;PMCID:PMC8039017. 
3. Thylefors B. Epidemiological patterns of ocular trauma. Aust N Z J Ophthalmol. 1992;20:95-98. https://pubmed.ncbi.nlm.nih.gov/1389141/. https://scholar.google.com/scholar_ lookup?journal=Aust $+\mathrm{N}+\mathrm{Z}+\mathrm{J}+\mathrm{Oph}$ thalmol\&title $=$ Epidemiological+patterns+of+ocular+trauma \&author=B+Thylefors\&volume $=20 \&$ publication year $=1992 \&$ pages $=95-98 \&$ pmid $=1389141$.

4. Norbder E. Injuries as a public health problem in subSaharan Africa: epidemiology and prospects for control. East Afr Med J. 2000;77:1-43.

5. Truma ISoO. Birmingham eye trauma terminology system. https://isotonline.org/betts/. Accessed 29 May 2020.

6. Fong LP. Eye injuries in Victoria, Australia. Med J Aust. 1995;162(2):64-8. https://onlinelibrary.wiley. com/doi/abs/10.5694/j.1326-5377.1995.tb138434. $\mathrm{x}$.

7. Long J, Mitchell R. Hospitalised eye injuries in New South Wales, Australia. Open Epidemiol J. 2009;2: 1-7. https://benthamopen.com/ABSTRACT/ TOEPIJ-2-1.

8. Pieramici DJ, Sternberg P Jr, Aaberg TM Sr, Bridges WZ Jr, Capone A Jr, Cardillo JA, de Juan Jr E, Kuhn F, Meredith TA, Mieler WF, Olsen TW, Rubsamen P, Stout T. A system for classifying mechanical injuries of the eye (globe). The Ocular Trauma Classification Group. Am J Ophthalmol. 1997;123(6):820-31.

9. Li X, Zarbin MA, Bhagat N. Pediatric open globe injury: a review of the literature. J Emerg Trauma Shock. 2015;8(4):216-23. https://www.ncbi.nlm. nih.gov/pmc/articles/PMC4626939/. https:// pubmed.ncbi.nlm.nih.gov/26604528/.

10. Onakpoya OH, Adeoye A, Adeoti CO, Ajite K. Epidemiology of ocular trauma among the elderly in a developing country. Ophthalmic Epidemiol. 2010;17(5):315-20.

11. Kadappu S, Silveira S, Martin F. Aetiology and outcome of open and closed globe eye injuries in children. Clin Exp Ophthalmol. 2013;41(5):427-34.

12. Heidari E, Taheri N. Surgical treatment of severely traumatized eyes with no light perception. Retina. 2010;30(2):294-9.

13. Madhusudhan AL, Evelyn-Tai LM, Zamri N, Adil H, Wan-Hazabbah WH. Open globe injury in Hospital Universiti Sains Malaysia - a 10-year review. Int J Ophthalmol. 2014;7(3):486-90.

14. Makhrash MA, Gosadi IM. Open globe eye injury characteristics and prognostic factors in Jazan, Saudi Arabia. Saudi Med J. 2016;37(12):1328.
15. Agrawal R, Wei HS, Teoh S. Prognostic factors for open globe injuries and correlation of ocular trauma score at a tertiary referral eye care centre in Singapore. Indian J Ophthalmol. 2013;61:502-6.

16. Larque-Daza AB, Peralta-Calvo J, Lopez-Andrade J. Epidemiology of open-globe trauma in the southeast of Spain. Eur J Ophthalmol. 2010;20:578-83.

17. Groessl S, Nanda SK, Mieler WF. Assault-related penetrating ocular injury. Am J Ophthalmol. 1993;116(1):26-33.

18. Smith D, Wrenn K, Stack LB. The epidemiology and diagnosis of penetrating eye injuries. Acad Emerg Med. 2002;9(3):209-13.

19. Esmaeli B, Elner SG, Schork MA, Elner VM. Visual outcome and ocular survival after penetrating trauma: a clinicopathologic study. Ophthalmology. 1995;102(3):393-400.

20. Wong TY, Tielsch JM. A population-based study on the incidence of severe ocular trauma in Singapore. Am J Ophthalmol. 1999;128(3):345-51.

21. Rahman I, Maino A, Devadason D, Leatherbarrow B. Open globe injuries: factors predictive of poor outcome. Eye. 2006;20(12):1336-41.

22. Sheard RM, Mireskandari K, Ezra E, Sullivan PM. Vitreoretinal surgery after childhood ocular trauma. Eye. 2007;21:793-8.

23. Hosseini H, Masoumpour M, Keshavarz-Fazl F, Razeghinejad MR, Salouti R, Nowroozzadeh MH. Clinical and epidemiologic characteristics of severe childhood ocular injuries in Southern Iran. Middle East Afr J Ophthalmol. 2011;18:136-40.

24. Al-Mahdi HS, Bener A, Hashim SP. Clinical pattern of pediatric ocular trauma in fast developing country. Int Emerg Nurs. 2011;19:186-91.

25. Liu ML, Chang YS, Tseng SH, Cheng HC, Huang FC, Shih $\mathrm{MH}$, et al. Major pediatric ocular trauma in Taiwan. J Pediatr Ophthalmol Strabismus. 2010;47: 88-95.

26. Abbott J, Shah P. The epidemiology and etiology of pediatric ocular trauma. Surv Ophthalmol. 2013;58: $476-85$.

27. Chakraborti C, Giri D, Choudhury KP, Mondal M, Datta J. Paediatric ocular trauma in a tertiary eye care center in Eastern India. Indian J Public Health. 2014;58:278-80.

28. Skiker H, Laghmari M, Boutimzine N, Ibrahimy W, Benharbit M, Ouazani B, et al. Open globe injuries in children: retrospective study of 62 cases. Bull Soc Belge Ophtalmol. 2007;306:57-61. 
29. Narang S, Gupta V, Simalandhi P, Gupta A, Raj S, Dogra MR. Paediatric open globe injuries. Visual outcome and risk factors for endophthalmitis. Indian J Ophthalmol. 2004;52:29-34.

30. Lesniak SP, Bauza A, Son JH, Zarbin MA, Langer P, Guo S, et al. Twelve-year review of pediatric traumatic open globe injuries in an urban U.S. population. J Pediatr Ophthalmol Strabismus. 2012;49: 73-9.

31. Liu X, Liu Z, Liu Y, Zhao L, Xu S, Su G, et al. Determination of visual prognosis in children with open globe injuries. Eye. 2014;28:852-6.

32. Ilhan HD, Bilgin AB, Cetinkaya A, Unal M, Yucel I. Epidemiological and clinical features of paediatric open globe injuries in Southwestern Turkey. Int J Ophthalmol. 2013;6:855-60.

33. Lee CH, Lee L, Kao LY, Lin KK, Yang ML. Prognostic indicators of open globe injuries in children. Am J Emerg Med. 2009;27:530-5.

34. Patel SN, Langer PD, Zarbin MA, Bhagat N. Diagnostic value of clinical examination and radiographic imaging in identification of intraocular foreign bodies in open globe injury. Eur J Ophthalmol. 2012;22(2):259-68.

35. Nirmalan PK, Katz J, Tielsch JM, Robin AL, Thulasiraj RD, Krishnadas R, Ramakrishnan R. Ocular trauma in a rural south Indian population: the Aravind Comprehensive Eye Survey. Ophthalmology. 2004;111(9):1778-81.

36. Bunting H, Stephens D, Mireskandari K. Prediction of visual outcomes after open globe injury in children: a 17-year Canadian experience. J AAPOS. 2013;17:43-8.

37. Saxena R, Sinha R, Purohit A, Dada T, Vajpayee RB, Azad RV. Pattern of pediatric ocular trauma in India. Indian J Pediatr. 2002;69:863-7.

38. Baiyeroju-Agbeja AM, Olurin-Aina OI. Penetrating eye injuries in children in Ibadan. Afr J Med Med Sci. 1998;27:13-5.

39. Lee $\mathrm{CH}, \mathrm{Su} \mathrm{WY}$, Lee L, Yang ML. Pediatric ocular trauma in Taiwan. Chang Gung Med J. 2008;31: 59-65. 